\title{
Delayed Diagnosis of Isolated Traumatic Rupture of Bladder
}

\author{
Mamadou Traoré1, N'diamoi Akassimadou'2, Kouakou Ibrahim Anzoua1, \\ Kouame Bernadin Kouakou', Inza Bamba1, Kouassi Patrice Avion², Brice Aguia'2, \\ Kalou Ismaël Leh Bi'1, Ahou Bernadette N'Dri' ${ }^{1}$, Serge Amos Ekra1, \\ Blaise Amos Kouakou', Roger Lebeau' ${ }^{1}$, Bamourou Diané1
}

${ }^{1}$ Department of General and Digestive Surgery, University Hospital of Bouaké, Bouaké, Côte d'Ivoire ${ }^{2}$ Department of Urology, University Hospital of Bouaké, Bouaké, Côte d'Ivoire

Email: ndiamoi74@gmail.com

How to cite this paper: Traoré, M., Akassimadou, N., Anzoua, K.I., Kouakou, K.B., Bamba, I., Avion, K.P., Aguia, B., Leh Bi, K.I., N’Dri, A.B., Ekra, S.A., Kouakou, B.A., Lebeau, R. and Diané, B. (2022) Delayed Diagnosis of Isolated Traumatic Rupture of Bladder. Open Journal of Urology, 12, 69-73. https://doi.org/10.4236/oju.2022.121007

Received: November 4, 2021

Accepted: January 21, 2022

Published: January 24, 2022

Copyright () 2022 by author(s) and Scientific Research Publishing Inc. This work is licensed under the Creative Commons Attribution International License (CC BY 4.0).

http://creativecommons.org/licenses/by/4.0/

\begin{abstract}
Traumatic ruptures of the bladder are relatively rare lesions. They are associated in more than $80 \%$ of cases with a fracture of the pelvic girdle. The lesion mechanism is usually a sudden compression on the full bladder. Hypogastric pain and macroscopic hematuria suggest the diagnosis, which is confirmed by cystography. This diagnosis can be difficult and delayed in the absence of these call signs. We report a case of isolated traumatic intraperitoneal rupture of the bladder, diagnosed 24 hours after a public road accident in a 44-year-old patient.
\end{abstract}

\section{Keywords}

Contusion, Cystography, Rupture, Bladder

\section{Introduction}

Traumatic ruptures of the bladder are relatively rare lesions; less than $1 \%$ of abdominal contusions [1] [2]. They are associated in more than $80 \%$ of cases with a fracture of the pelvic girdle [3]. Vesical lesions are more rarely isolated [4] [5]. These isolated ruptures most often occur in the course of road accidents. The lesion mechanism is usually a sudden compression on the full bladder [6]. Hypogastric pain and macroscopic hematuria evoke the diagnosis; diagnosis is confirmed by cystography [7]. This diagnosis may be difficult and delayed in the absence of these call signs [8]. A delay in management could increase morbidity-mortality by $10 \%-22 \%$ [9] [10]. We report a case of traumatic intraperitoneal rupture isolated from the bladder, diagnosed 24 hours after a road accident. 


\section{Observation}

Mr F.M, 44 years old, was admitted to the surgical emergency at the Teaching Hospital of Bouaké for an abdominal-pelvic contusion that had occurred 1 hour earlier. He was a driver of a personal vehicle and was wearing a seat belt. The vehicle would have gone off the road followed by a roll. He was held in his seat by the belt. At admission, the patient was conscious with good hemodynamic vitals. The examination noted sensitivity to the hypogastrium. There was no evidence of peritoneal irritation or peritoneal fluid effusion. There was no hematuria. The $\mathrm{X}$-ray of the pelvis was normal. Administration of analgesics had calmed the pain. We put the patient at observation to regard the hemodynamic constanties and to realize blood test. The patient was released 6 hours later. Twenty-four hours later, the patient has consulted for abdominal distension and complete absence of urination without urinary tenesmus since the accident. Clinical examination revealed hypogastric pain, peritoneal fluid effusion, no signs of peritonitis, and absence of full bladder.

The abdominal-pelvic ultrasound showed a high-abundance fluid effusion and complete rupture of the bladder dome wall (Figure 1).

The blood test (complete blood count, uremia, serum creatinine, blood electrolytes) was free of abnormalities. The installation of a foley catheter brought back just $50 \mathrm{ml}$ of clear urine.

The diagnosis of intraperitoneal rupture of the bladder was retained and an exploratory laparotomy was indicated. In intraoperative, $2200 \mathrm{ml}$ of clear urine was aspirated and a $3 \mathrm{~cm}$-long wound with contused edges was found on the vesical dome (Figure 2). The wound was sutured in two planes with absorbable suture (Figure 3) and the bladder catheter was left in place. The tightness of the suture was tested in intraoperative by filling the bladder with physiological serum. The follow-up was simple. The discharge was allowed on day 3 postoperative. The catheter was removed on day 10 postoperative.

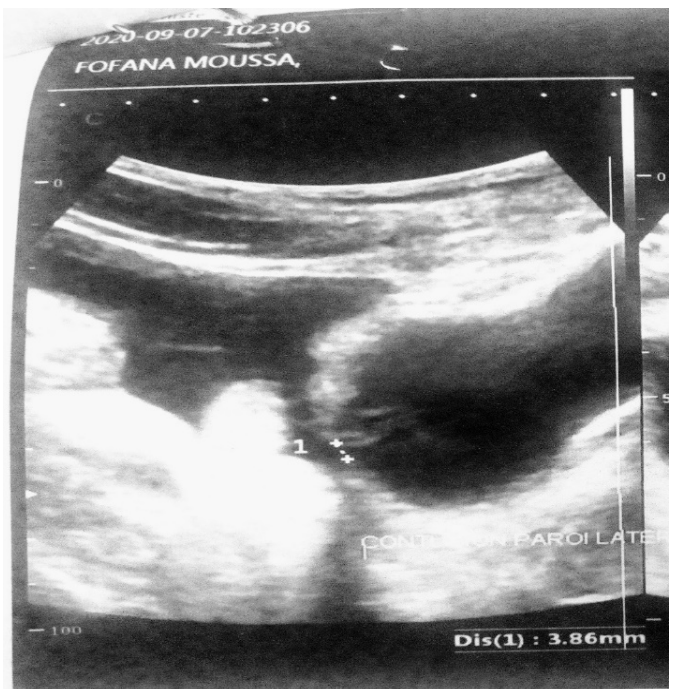

Figure 1. Rupture of the bladderdomewall on ultrasound. 


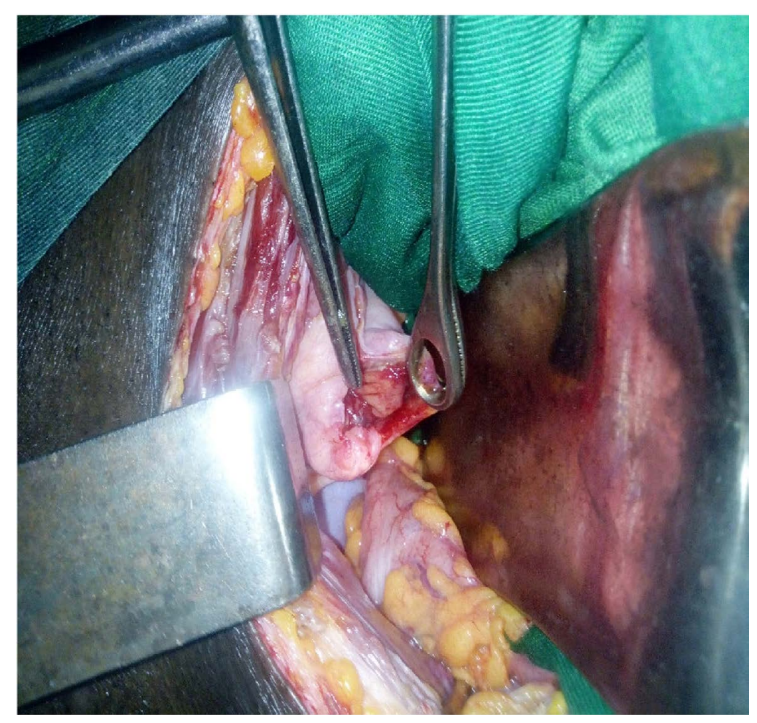

Figure 2. Post traumatic rupture of the bladderdome during surgery.

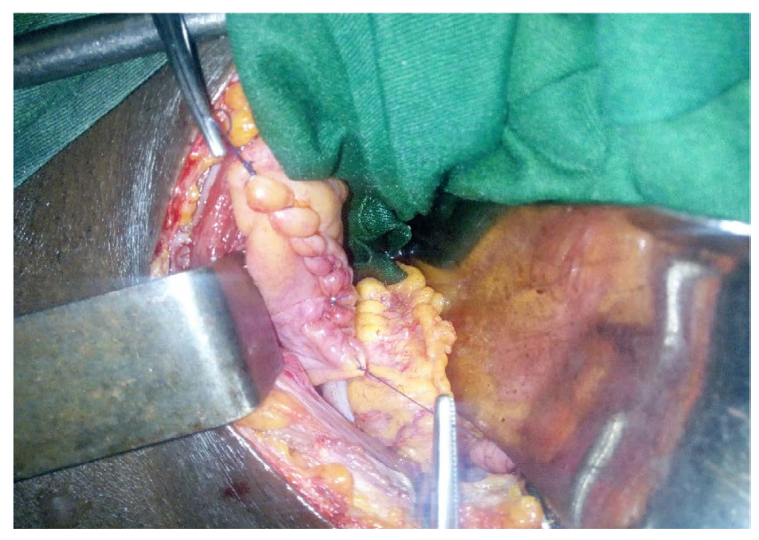

Figure 3. Cystorrhaphy by a suture with absorbable suture.

\section{Commentary}

We reported one case of isolated intraperitoneal rupture of the bladder, with no associated injury, due to compression of the seat belt.

Traumatic ruptures of the bladder are relatively rare lesions; less than $1 \%$ of abdominal contusions [1] [2]. They are associated in more than $80 \%$ of cases with a fracture of the pelvic girdle [3]. Bladder ruptures can be intraperitoneal, extra-peritoneal (sub-peritoneal) or mixed. Isolated ruptures of the bladder are essentially intraperitoneal in contrast to sub-peritoneal lesions, which are very often associated with fractures of the pelvis that are responsible for bladder pinning [4] [5] [6]. The mechanism of injury of isolated intraperitoneal bladder lesions is most often sudden compression on a full bladder. These ruptures often occur at the level of the dome where the wall is mobile, attenuated and predisposed to swell.

Extra-peritoneal ruptures are more common ( $80 \%$ of cases), usually occur as part of a pelvic fracture and involve the anterolateral wall of the bladder, trigone 
and neck of the bladder. A minority of patients combined intraperitoneal and extra-peritoneal lesions (5\% of cases) [7] [8] [9].

The diagnosis of bladder injury is evident in the presence of hypogastric pain associated with macroscopic hematuria. This macroscopic hematuria is present in more than $95 \%$ of patients with bladder lesions [10] [11] [12]. But this diagnosis can be delayed by 24 hours or more when the signs are insidious or when they appear secondarily, in particular an absence of urination without a bladder [4] [5]. This was the case in our patient where the diagnosis was suggested 24 hours after the accident due to the absence of urination without tenesmus, hypogastric pain and distension. The definitive diagnosis of bladder injury is provided by imaging. Ultrasound is the first-line examination. This is an orientation exam for a ruptured bladder. It shows a perivesical or intraperitoneal effusion [7]. In our case, ultrasound, in addition to objectifying intraperitoneal fluid effusion, showed the rupture of the wall of the bladder dome (Figure 1). Retrograde cystography is the exam of choice. Its sensitivity is estimated between $80 \%$ and $100 \%$ [13]. Although conventional radiographic cystography has traditionally been considered the standard of reference in the detection of bladder lesions, computed tomography cystography has become the initial imaging method of choice in the acute context [7].

The therapeutic attitude in front of a bladder rupture depends on the anatomopathological type. Treatment of intraperitoneal bladder ruptures is exclusively surgical. It combines a cystorrhaphy by overcast seam of absorbable suture with a bladder drainage by a urethral catheter of large caliber. This was the case with our patient. As for subperitoneal bladder ruptures, the treatment is conservative; drainage by a urethral catheter of a large caliber is sufficient. Most breaches heal under these conditions. $85 \%$ are closed on the 10th day of drainage and virtually $100 \%$ are tight by the end of the 3rd week [13] [14].

\section{Conclusion}

Isolated bladder ruptures are rare lesions. They are mostly intraperitoneal. Their clinical expressions are often delayed, resulting in a diagnostic and therapeutic delay. They must be actively sought during abdominal-pelvic trauma even in the absence of a pelvic fracture.

\section{Conflicts of Interest}

The authors declare no conflicts of interest regarding the publication of this paper.

\section{References}

[1] Matlock, K.A., Tyroch, A.H., Kronfol, Z.N., McLean, S.F. and Pirela-Cruz, M.A. (2013) Blunt Traumatic Bladder Rupture: A 10-Year Perspective. The American Surgeon, 79, 589-593. https://doi.org/10.1177/000313481307900619

[2] Elkbuli, A., Ehrhardt, J.D., Hai, S., McKenney, M. and Boneva, D. (2019) Manage- 
ment of Blunt Intraperitoneal Bladder Rupture: Case Report and Literature Review. International Journal of Surgery Case Reports, 55, 160-163. https://doi.org/10.1016/j.ijscr.2019.01.038

[3] Gomez, R.G., Ceballos, L., Coburn, M., et al. (2004) Consensus Statement on Bladder Injuries. BJU International, 94, 27-32. https://doi.org/10.1111/j.1464-410X.2004.04896.x

[4] Alhamzawi, H.H., Abdelrahman, H.M., Abdelrahman, K.M., El-Menyar, A., Al-Thani, H. and Latifi, R. (2012) Delayed Presentation of Traumatic Intraperitoneal Rupture of Urinary Bladder. Case Reports in Urology, 2012, Article ID 430746. https://doi.org/10.1155/2012/430746

[5] Sewa, E.V., Kpatcha, M.T., Tengue, K., Botcho, G., Sikpa, K.H., Anoukoum, T., Madougou, M., Sambiani, F.S. and Dosseh, E.D. (2016) Uropéritoine aigu révélant une rupture traumatique isolée de la vessie: A propos d'un cas et revue de la littérature. Journal de la Recherche Scientifique de I Université de Lomé, 18, Series B, D, E.

[6] Hsieh, C.H., Chen, R.J., Fang, J.F., et al. (2002) Diagnosis and Management of Bladder Injury by Trauma Surgeons. American Journal of Surgery, 184, 143-147. https://doi.org/10.1016/S0002-9610(02)00913-3

[7] Fouladi, D.F., Shayesteh, S., Fishman, E.K. and Chu, L.C. (2020) Imaging of Urinary Bladder Injury: The Role of CT Cystography. Emergency Radiology, 27, 87-95. https://doi.org/10.1007/s10140-019-01739-3

[8] Deem, S., Lavender, C.D. and Agarwal, S. (2007) Delayed Presentation of Traumatic Bladder Injury: A Case Report and Review of Current Treatment Trends. The Internet Journal of Urology, 5, $8 \mathrm{p}$.

[9] Bryk, D.J. and Zhao, L.C. (2016) Guideline of Guidelines: A Review of Urological Trauma Guidelines. BJU International, 117, 226-234. https://doi.org/10.1111/bju.13040

[10] Pereira, B.M., De Campos, C.C., Calderan, T.R., Reis, L.O. and Fraga, G.P. (2013) Bladder Injuries after External Trauma: 20 Years Experience Report in a Population-Based Cross-Sectional View. World Journal of Urology, 31, 913-917. https://doi.org/10.1007/s00345-012-0871-8

[11] Mahat, Y., Leong, J.Y. and Chung, P.H. (2019) A Contemporary Review of Adult Bladder Trauma. Journal of Injury and Violence Research, 11, 101-106. https://doi.org/10.5249/jivr.v11i2.1069

[12] Morey, A.F., Iverson, A.J., Swan, A., Harmon, W.J., Spore, S.S., Bhayani, S., Brandes, S.B. (2001) Bladder Rupture after Blunt Trauma: Guidelines for Diagnostic Imaging. The Journal of Trauma: Injury, Infection, and Critical Care, 51, 683-686. https://doi.org/10.1097/00005373-200110000-00010

[13] Lynch, T.H. and Martinez-Pineiro, L. (2005) Guidelines on Urogical Trauma. European Urology, 47, 1-5. https://doi.org/10.1016/j.eururo.2004.07.028

[14] Corriere, J.N. and Sandler, C.M. (2006) Diagnosis and Management of Bladder Injuries. Urologic Clinics of North America, 33, 67-71.

https://doi.org/10.1016/j.ucl.2005.10.003 